\title{
(2) OPEN ACCESS \\ Exposure to tobacco imagery in popular films and the risk of ever smoking among children in southern India
}

\author{
Muralidhar M Kulkarni 이, ' Veena Ganesh Kamath 이, ${ }^{1}$ Asha Kamath, ${ }^{2}$ Sarah Lewis, ${ }^{3}$ \\ Ilze Bogdanovica, ${ }^{3}$ Manpreet Bains, ${ }^{3}$ Jo Cranwell, ${ }^{4}$ Andrew Fogarty, ${ }^{3}$ Monika Arora, ${ }^{5,6}$ \\ Gaurang P Nazar (1) ${ }^{5}$ Kirthinath Ballal, ${ }^{1}$ Rohith Bhagwath, ${ }^{1}$ John Britton ${ }^{3}$
}

\begin{abstract}
- Additional material is published online only. To view please visit the journal online (http://dx.doi.org/10.1136/ tobaccocontrol-2019-055353).

${ }^{1}$ Community Medicine, Kasturba Medical College, Manipal Academy of Higher Education, Udupi, India

${ }^{2}$ Department of Data Science, Prasanna School of Public Health, Manipal Academy of Higher Education, Udupi, India ${ }^{3}$ Division of Epidemiology and Public Health, UK Centre for Tobacco and Alcohol Studies, University of Nottingham, Nottingham, UK ${ }^{4}$ Department of Health, University of Bath, Bath, UK ${ }^{5}$ Health Related Information Dissemination Amongst Youth (HRIDAY), New Delhi, India ${ }^{6}$ Health Promotion, Public Health Foundation of India, New Delhi, India
\end{abstract}

\section{Correspondence to} Dr Veena Ganesh Kamath, Community Medicine, Kasturba Medical College, Manipal Academy of Higher Education, Udupi 576104, India; veenak@manipal.edu

Received 29 August 2019 Revised 9 June 2020 Accepted 10 June 2020

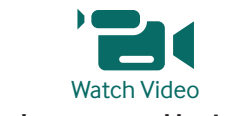
tobaccocontrol.bmj.com

Check for updates

(C) Author(s) (or their employer(s)) 2020. Re-use permitted under CC BY. Published by BMJ.

To cite: Kulkarni MM, Kamath VG, Kamath A, et al. Tob Control Epub ahead of print: [please include Day Month Year]. doi:10.1136/ tobaccocontrol-2019-055353

\section{ABSTRACT}

Background Exposure to smoking in films is a recognised cause of smoking uptake among children. In India, in an attempt to protect children, films containing smoking are required to include tobacco control messaging including audiovisual disclaimers, on-screen health warnings when tobacco imagery is displayed and antitobacco 'health spots' before and during the film. We report a study of the association between ever smoking and exposure to tobacco imagery in locally popular films among children in Udupi district of Karnataka state in southern India.

Methods A cross-sectional questionnaire survey of all students in grades 6-8 in schools in the Udupi district ascertained smoking status and potential confounders of smoking uptake, and whether children had seen any of 27 locally popular films we had coded and found to contain imagery of actual or implied tobacco use. Eversmoking status was defined as any reported smoking of cigarettes, beedis or other tobacco products currently or at any time in the past. Independent effects on eversmoking status were estimated using multiple logistic regression.

Results of 46706 students enrolled in grades 6-8 in 914 participating schools, 39282 (84.1\%) provided questionnaire responses sufficiently complete for analysis. Ever smoking was reported by 914 (2.3\%) participants and in a mutually adjusted model was significantly related to age, male sex, living in a home where smoking is allowed, having parents or siblings who smoke, low paternal education, low levels of family wealth, low self-esteem, rebelliousness and poor school performance. After allowing for these effects, the odds of ever smoking were not increased among students who had seen any of the listed films containing tobacco imagery when included in the analysis as a binary exposure (OR 0.9, 95\% Cl 0.4 to 2.0), and decreased in relation to level of exposure graded into tertiles of tobacco intervals seen.

Conclusions In this cross-sectional study, children in southern India who had seen films containing tobacco imagery are no more likely to smoke than those who had not, indicating that the tobacco control messaging mandated by Indian law may be attenuating the effect of tobacco imagery in films on smoking uptake.

\section{INTRODUCTION}

Smoking causes an estimated 7 million deaths each year, ${ }^{12}$ and around $80 \%$ of these deaths from tobacco now occur in low and middle-income countries. ${ }^{12}$ Smoking prevention is thus a global health priority, and the growing implementation of Framework Convention for Tobacco Control (FCTC) represents substantial progress in this respect. ${ }^{2}$ One of the key components of comprehensive tobacco control policy is protecting children from exposure to imagery that promotes smoking. While Article 13 of the FCTC prohibits paid-for tobacco advertising and other forms of promotion, ${ }^{3}$ it does not prevent unpaid inclusion of smoking and other tobacco imagery in films, television, on-demand video services and other media popular with children.

There is now growing recognition that watching films containing tobacco imagery causes incident smoking among children, ${ }^{4-7}$ but most of the available evidence for this effect arises from studies carried out in high-income countries. ${ }^{8}$ India, a lower middle-income country that is home to one in six of the global population, has a thriving film industry, and Indian films produced in the late 20th century were shown to contain high levels of tobacco imagery. ${ }^{9}$ Evidence on the effect of film smoking exposure on smoking among children in India is limited to a study of exposure to Bollywood films among secondary school-age children in Delhi ${ }^{10}$ in 2009. Since then the Indian government has introduced tobacco control legislation requiring that screenings of films containing tobacco imagery include an audiovisual (AV) disclaimer at the start of the film, health warnings during scenes containing tobacco and antismoking 'health spots' before and during the film. ${ }^{11}$ We now report a study of the association between smoking and exposure to tobacco imagery in locally popular films among children in a mixed urban and rural area of Karnataka state in southern India to determine whether smoking imagery in a range of Bollywood, international and local (southern Indian) films is associated with an increased risk of ever smoking.

\section{METHODS}

We used a cross-sectional questionnaire survey to measure smoking and exposure to smoking imagery in the media and other potential causal exposures and confounders in students in grades 6,7 and 8 (aged between 10 and 15 years) attending any of the more than 700 government, 250 government-aided and 200 privately funded schools in the five educational administrative blocks (Udupi, Brahmavar, Karkala, Kundapura, Byndoor) in Udupi district of Karnataka state in India. We used a list comprising all government, private and aided schools obtained from the Udupi District Education Department to contact school principals and arrange a visit by 
a member of the survey staff to explain the study and obtain written consent for school participation. After obtaining the principal's consent, researchers visited the school twice: first, to distribute a study information sheet for students and parental information and opt-out consent forms to all students in grades 6-8; and second, during a period of approximately $45 \mathrm{~min}$ scheduled into the schoolday 3-14 days later, to distribute questionnaires for completion by all consenting students whose parents did not exercise the opt-out. As school attendance rates are high we studied only those children present on the arranged study day; if for any reason (eg, heavy monsoon rains) fewer than $80 \%$ of students were in attendance, the survey was rescheduled. The student enrolment number issued by the education department was used as unique identifier for each participant. Data were collected between July 2017 and January 2018.

\section{Questionnaire design and study variables}

The questionnaire elicited information on current and past use of cigarettes, beedis and a range of other smoked tobacco including cigars, cheroots, chillum, chutta and rolled cigarettes, ${ }^{12}$ with frequency of use (never; ever but not now; less than once a week; once a week; daily) using questions adapted from the Global Youth Tobacco Survey (GYTS), ${ }^{13}$ the UK Smoking, Drinking and Drug Use Survey, ${ }^{14}$ and Health Related Information Dissemination Amongst Youth's Mobilizing Youth for Tobacco-Related Initiatives in India project. ${ }^{15}$ Questions on exposure to and awareness of tobacco products in retail outlets, including brand recognition, were drawn from the Nottingham Schools study. ${ }^{16}{ }^{17}$ Awareness of health warnings and mass media campaigns were evaluated using questions from the GYTS India and Nottingham Schools surveys, adapted to include awareness of graphic and printed health warnings, and recall of exposure to tobacco control media campaigns.

Questions on exposure to tobacco imagery in films asked students whether they had seen any of 27 most popular films in Karnataka in the 2 years (2015 and 2016) preceding the study that we had previously interval coded and demonstrated to contain tobacco imagery. ${ }^{11}$ As previously reported,${ }^{11}$ the most popular films were identified from national and local film distributor box-office ratings data, coded semiquantitatively using 5 min interval coding, and exposure quantified by summing the number of 5 min coded intervals containing tobacco imagery seen on the assumption of one complete viewing per film. ${ }^{11}$ Tobacco imagery was coded as actual use, implied use, tobacco paraphernalia and tobacco branding. The students were asked to mark if they had watched any of the listed films and as we had the details of number of tobacco intervals in each of the coded films, we could ascertain the exposure to tobacco imagery for each child. Film compliance with legal requirements under the Cigarettes and Other Tobacco Products Act (COTPA) $)^{18} 19$ regarding the inclusion of AV disclaimer, health spots of $30 \mathrm{~s}$ before and during the film and on-screen health warnings during scenes including smoking was also coded. ${ }^{11}$

Questions were included on the smoking policies adopted by the respondent's school and in the family home, and on family smoking, peer smoking, self-esteem and rebelliousness. ${ }^{20-22}$ We measured socioeconomic status through a question on ownership of household goods, grouping participants into quintiles of family wealth. ${ }^{23}$ Other variables included age, gender, religion, academic grades in the past year, expectation of academic achievement, parents' education and occupation. The questionnaire was piloted in a school in the neighbouring district and refined before use.

\section{Data analysis}

Data were extracted from completed questionnaires into Microsoft Excel using Optical Mark Reader scanning and transferred into STATA V.9.2 software for analysis. Ever smoking was defined as any reported smoking of any tobacco product, currently or in the past. Associations between ever smoking and ordered or categorical variables were evaluated using logistic regression to estimate the effects of potential explanatory variables on the risk of smoking. Demographic variables were explored first and all that were significantly $(\mathrm{p}<0.05)$ associated with ever smoking were retained in the model. We then created a model which included all independently significant determinants of having ever smoked to then test the significance of measures of exposure to tobacco imagery in films first as a binary exposure (having seen or not seen a film containing at least one interval including tobacco imagery) and then as a graded variable in four categories (no exposure, and tertiles of those exposed). We also carried out an exploratory analysis to determine the effect on ever smoking of exposure to film smoking imagery in films according to the presence or absence of individual components of tobacco-free film rules required under COTPA. (Please refer to the online supplementary appendix for further details regarding study variables and analysis.)

\section{RESULTS}

Of the total of 1214 schools in Udupi district listed by the education department we excluded 5 that had closed, 7 that were special schools for differently abled children and 281 lower primary and 2 high schools with no students in grades $6-8$. We contacted the principals of the remaining 919 schools, and 914 (99.4\%) of these consented to participate. Of the 46706 students in grades 6-8 in 914 schools, 3066 were absent on the day of the survey, 271 declined to participate, 315 were excluded by parental opt-out and 6 students consented but did not complete a questionnaire. The five schools that declined to participate, and 507 of the 586 students who themselves or whose parents declined consent were all from private schools. The remaining 43048 students (92.2\%) completed the survey questionnaire. After excluding 3766 questionnaires with insufficient or otherwise unusable data, 39282 questionnaires (representing 84.1\% of the eligible students in consenting schools) were available for analysis. The 3766 questionnaires were either not completed by the students or had made contradicting responses and hence were not included for analysis. Respondents included similar proportions of males (51\%) and females (49\%), and of students from grades 6,7 and $8(32.5 \%, 33.6 \%$ and $33.9 \%$, respectively). Most participants were of Hindu religion (83.3\%) and from rural areas $(80.1 \%)$.

Ever smoking was reported by 914 (2.3\%) participants and in univariate analysis varied significantly by age, was more prevalent among male participants, those attending governmentfunded or part-funded schools, those who were not Hindus, who had family members or friends who smoked, lived in a home where smoking is allowed, attended a school where smoking was seen, whose parents were less educated, whose families were relatively poor and who were rebellious, reported low self-esteem and had poor performance at school (table 1). In a mutually adjusted model retaining independently significant associations, smoking was related to age, being male, living in a home where smoking is allowed, having parents, siblings or friends who smoke, low paternal education, low levels of family wealth, low self-esteem, rebelliousness and poor performance at school (table 1). 
Table 1 Demographic and environmental associations with smoking in the study population, with univariate and independently significant mutually adjusted ORs

\begin{tabular}{|c|c|c|c|c|c|c|}
\hline \multirow[b]{2}{*}{ Characteristic } & \multirow[b]{2}{*}{ n (\%) } & \multirow[b]{2}{*}{ Ever smokers (\%) } & \multirow{2}{*}{$\begin{array}{l}\text { Crude OR } \\
(95 \% \mathrm{Cl})\end{array}$} & \multirow[b]{2}{*}{$P$ value } & \multirow{2}{*}{$\begin{array}{l}\text { Adjusted OR* } \\
(95 \% \mathrm{CI})\end{array}$} & \multirow[t]{2}{*}{$P$ value } \\
\hline & & & & & & \\
\hline Age & & & $<0.001$ & & & 0.510 \\
\hline 11 & $5760(14.7)$ & $161(2.8)$ & 0.7 (0.3 to 1.3$)$ & & $1.9(0.6$ to 6.1$)$ & \\
\hline 12 & 12932 (32.9) & $328(2.5)$ & 0.6 (0.3 to 1.2$)$ & & 1.7 (0.5 to 5.4$)$ & \\
\hline 13 & 13247 (33.7) & $277(2.1)$ & $0.5(0.3$ to 1.0$)$ & & 1.7 (0.5 to 5.4$)$ & \\
\hline Gender & & & & $<0.001$ & & 0.003 \\
\hline Male & $20020(51.0)$ & $597(3.0)$ & 1.8 (1.6 to 2.1$)$ & & 1.3 (1.1 to 1.6$)$ & \\
\hline Female & $19262(49.0)$ & $317(1.6)$ & 1 & & 1 & \\
\hline School locality & & & & 0.773 & & - \\
\hline Urban & $7803(19.9)$ & $185(2.4)$ & 1.02 (0.9 to 1.2$)$ & & & \\
\hline Private & $14912(38.0)$ & $271(1.8)$ & 1 & & 1 & \\
\hline Religion & & & & $<0.001$ & & 0.068 \\
\hline Hindu & $32713(83.3)$ & $710(2.2)$ & 1 & & 1 & \\
\hline Christian & $2016(5.1)$ & $51(2.5)$ & $1.2(0.9$ to 1.6$)$ & & 1.1 (0.8 to 1.6$)$ & \\
\hline Jain & $152(0.4)$ & $7(4.6)$ & $2.2(1.0$ to 4.7$)$ & & 1.7 (0.6 to 5.2$)$ & \\
\hline Muslim & $4272(10.9)$ & $138(3.2)$ & 1.5 (1.3 to 1.8$)$ & & 1.4 (1.1 to 1.8$)$ & \\
\hline Other & $129(0.3)$ & $8(6.2)$ & $3.0(1.5$ to 6.1$)$ & & $1.6(0.6$ to 4.2$)$ & \\
\hline Home smoking tobacco use allowed & & & & $<0.001$ & & $<0.001$ \\
\hline No & $35400(90.1)$ & $588(1.7)$ & 1 & & 1 & \\
\hline Yes & $3882(9.9)$ & $326(8.4)$ & 5.4 (4.7 to 6.2$)$ & & $2.8(2.3$ to 3.4$)$ & \\
\hline Others: Yes & $6119(15.6)$ & $160(2.6)$ & $1.2(1.0$ to 1.4$)$ & 0.104 & & - \\
\hline No & $33163(84.4)$ & $754(2.3)$ & 1 & & & \\
\hline Friends smoking tobacco use & & & & $<0.001$ & & $<0.001$ \\
\hline None & $34430(87.6)$ & $352(1.0)$ & 1 & & 1 & \\
\hline One & $763(1.9)$ & $132(17.3)$ & 20.3 (16.3 to 25.1$)$ & & $10.8(8.1$ to 14.4$)$ & \\
\hline Two & $492(1.3)$ & $137(27.9)$ & $37.4(29.9$ to 46.7$)$ & & 16.5 (12.2 to 22.4$)$ & \\
\hline Three & $579(1.5)$ & $121(20.9)$ & 25.6 (20.4 to 32.0$)$ & & 11.9 (8.7 to 16.2$)$ & \\
\hline Not sure & $3018(7.7)$ & $172(5.7)$ & $5.9(4.9$ to 7.0$)$ & & $4.0(3.1$ to 5.0$)$ & \\
\hline Smoking seen in school & & & & $<0.001$ & & 0.926 \\
\hline No & $28218(71.8)$ & $545(1.9)$ & 1 & & 1 & \\
\hline Yes & $11064(28.2)$ & $369(3.3)$ & $1.8(1.5$ to 2.0$)$ & & $1.0(0.8$ to 1.2$)$ & \\
\hline Mother's education & & & & $<0.001$ & & 0.425 \\
\hline Illiterate & $2457(6.4)$ & $94(3.8)$ & 4.3 (2.5 to 7.7$)$ & & 1.1 (0.6 to 2.4 ) & \\
\hline Primary & $16255(42.0)$ & $407(2.5)$ & 2.8 (1.6 to 4.8$)$ & & 0.9 (0.5 to 1.8$)$ & \\
\hline High school & 14466 (37.4) & $325(2.2)$ & 2.5 (1.5 to 4.3$)$ & & 1.1 (0.6 to 2.1 ) & \\
\hline Graduate & $3964(10.2)$ & $53(1.3)$ & $1.4(0.8$ to 2.7$)$ & & $1.0(0.5$ to 2.0$)$ & \\
\hline Postgraduate & $1554(4.0)$ & $14(0.9)$ & 1 & & 1 & \\
\hline Father's education & & & & $<0.001$ & & 0.013 \\
\hline Illiterate & $1757(4.6)$ & $79(4.5)$ & 7.0 (12.5 to 3.9$)$ & & 2.8 (1.4 to 5.4$)$ & \\
\hline Primary & $16018(41.5)$ & $410(2.6)$ & $3.9(6.7$ to 2.3$)$ & & 2.6 (1.4 to 4.9$)$ & \\
\hline High school & $14535(37.7)$ & $326(2.2)$ & 3.4 (5.9 to 2.0$)$ & & 2.9 (1.6 to 5.4$)$ & \\
\hline
\end{tabular}




\begin{tabular}{|c|c|c|c|c|c|c|}
\hline & & & Crude OR & & Adjusted OR* & $P$ value \\
\hline Characteristic & n (\%) & Ever smokers (\%) & $(95 \% \mathrm{Cl})$ & $P$ value & $(95 \% \mathrm{Cl})$ & \\
\hline Graduate & $4129(10.7)$ & $67(1.6)$ & 2.5 (4.4 to 1.4$)$ & & 2.5 (1.3 to 4.8$)$ & \\
\hline Postgraduate & $2106(5.5)$ & $14(0.7)$ & 1 & & 1 & \\
\hline Wealth quintile & & & & $<0.001$ & & $<0.001$ \\
\hline Lower & 7735 (19.7) & $331(4.3)$ & 2.8 (2.3 to 3.4$)$ & & 2.7 (2.1 to 3.6) & \\
\hline Lower middle & 7315 (18.6) & $180(2.5)$ & $1.6(1.3$ to 2.0$)$ & & 1.5 (1.1 to 2.0$)$ & \\
\hline Middle & $8464(21.6)$ & $171(2.0)$ & $1.3(1.0$ to 1.6$)$ & & $1.4(1.0$ to 1.9$)$ & \\
\hline Upper middle & $7855(20.0)$ & $106(1.3)$ & 0.9 (0.7 to 1.1$)$ & & $1.0(0.7$ to 1.4$)$ & \\
\hline Upper & $7867(20.1)$ & $124(1.6)$ & 1 & & 1 & \\
\hline Rebelliousness & & & & $<0.001$ & & $<0.001$ \\
\hline No & $24500(62.4)$ & $311(1.3)$ & 1 & & 1 & \\
\hline Mild & $10917(27.8)$ & $260(2.4)$ & 1.9 (1.6 to 2.2$)$ & & 1.7 (1.4 to 2.1$)$ & \\
\hline Moderate & $3396(8.6)$ & $267(7.9)$ & 6.6 (5.7 to 7.9$)$ & & 3.8 (3.0 to 4.8$)$ & \\
\hline Severe & $469(1.2)$ & 76 (16.2) & 15.0 (11.5 to 19.7$)$ & & 6.4 (4.4 to 9.5) & \\
\hline High self-esteem & & & & $<0.001$ & & 0.001 \\
\hline Strongly agree & $18169(46.3)$ & $280(1.54)$ & 1 & & 1 & \\
\hline Agree & $8799(22.4)$ & $240(2.7)$ & $1.8(1.5$ to 2.1$)$ & & $1.3(1.0$ to 1.6$)$ & \\
\hline Neither agree or disagree & $6817(17.4)$ & $191(2.8)$ & $1.8(1.5$ to 2.2$)$ & & $1.2(1.0$ to 1.6$)$ & \\
\hline Disagree & 3099 (7.9) & $123(4.0)$ & 2.6 (1.7 to 3.3$)$ & & 1.8 (1.4 to 2.4$)$ & \\
\hline Strongly disagree & $2398(6.1)$ & $80(3.34)$ & 2.2 (2.1 to 2.8$)$ & & $1.4(1.0$ to 2.0$)$ & \\
\hline School performance & & & & $<0.001$ & & 0.001 \\
\hline Excellent & $15046(38.3)$ & $253(1.7)$ & 1 & & 1 & \\
\hline Good & $17993(45.8)$ & $342(1.9)$ & 1.1 (0.9 to 1.3$)$ & & $1.1(0.9$ to 1.3$)$ & \\
\hline Average & $5337(13.6)$ & $249(4.7)$ & 2.9 (2.4 to 3.4$)$ & & $1.4(1.1$ to 1.9$)$ & \\
\hline Below average & $906(2.3)$ & $70(7.7)$ & 4.9 (3.7 to 6.4 ) & & 1.9 (1.3 to 2.8$)$ & \\
\hline
\end{tabular}

*All $p<0.05$ after adjustment for gender, father's education, family members smoking, friends smoking, wealth quintile, rebelliousness, self-esteem and school performance. NS, not significant in mutually adjusted model.

\section{Exposure to smoking imagery or messaging and smoking behaviour}

In an analysis in which single variables were added to the mutually adjusted model described in table 1 , ever smokers were more likely than never smokers to report having participated in tobacco control activities, having seen or heard tobacco control messaging in the media or to have seen tobacco advertising (table 2). Almost all participants (38 698; 98.5\%) reported having seen at least one of the 27 films containing smoking imagery listed in the questionnaire, and when added to the mutually adjusted model were not significantly more likely to be smokers than those who were unexposed, either before (unadjusted OR $2.0,95 \%$ CI 0.9 to 4.2 ) or after (adjusted OR 0.9, 95\% CI 0.4 to 2.0) adjustment for the above variables (data not shown). When exposure to tobacco imagery in films was included as a graded variable with exposure categorised into tertiles of the number of intervals containing tobacco imagery seen by the participant, there was no significant difference between tertiles but there was a significant negative trend in the odds of smoking across tertiles, which in the adjusted model declined from an OR of 1.2 (95\% CI 0.5 to 2.6$)$ in the first tertile of exposure to an OR of 0.7 (95\% CI 0.3 to 1.6 ) in the highest tertile (table 2 ).

In an exploratory analysis of exposure to tobacco imagery in films categorised in relation to their compliance with COTPA smoke-free film rules it was observed that exposure to an AV disclaimer at the start of the film was associated with a significantly lower risk of smoking, but there were no significant associations between smoking and other measures of compliance (table 3).

\section{DISCUSSION}

This study demonstrates that ever smoking was uncommon among children in grades 6-8 in schools in Karnataka state in southern India, but more likely to have occurred among males and among children who live with smokers or have friends who smoke, live in low educational level and low-income families and in homes where smoking is allowed, who are more rebellious and have low self-esteem and poor school performance. After allowing for these effects, which are consistent with those previously reported in India ${ }^{24}$ and widely established in studies of smoking among young people elsewhere in the world, ${ }^{6}$ participants in this study were also independently more likely to have ever smoked if they had heard or seen tobacco control messages or participated in other antitobacco activities, but no more likely to smoke if they had seen any one or more of 27 locally popular films we had previously demonstrated to contain tobacco imagery. ${ }^{11}$ There was also evidence of a significant negative relation between smoking risk and level of exposure to smoking imagery in films.

The association with exposure to tobacco control activities and messaging is likely to reflect reverse causation, whereby young people who smoke are more likely to recall tobacco control messages, but our findings in relation to the effect of film imagery exposure on smoking risk conflict with existing evidence, predominantly from high-income countries, that exposure to smoking imagery in film is consistently associated with a greater likelihood of smoking. ${ }^{8}$ These associations can also be linked to use of outcome variable in our analysis, which is ever smoking and not current smoking as in most similar studies. 
Table 2 Exposure to smoking imagery or messaging and smoking behaviour

\begin{tabular}{|c|c|c|c|c|c|c|}
\hline Characteristic & n (\%) & Ever smokers (\%) & $\begin{array}{l}\text { Model } 1 * \text { Adjusted } \\
\text { OR* }(95 \% \mathrm{Cl})\end{array}$ & $P$ value & $\begin{array}{l}\text { Model } 2 \dagger \\
\text { Adjusted OR } \\
(95 \% \mathrm{Cl})\end{array}$ & $P$ value \\
\hline Class on health hazards of tobacco & & & & 0.003 & & \\
\hline Yes & $7917(20.2)$ & $243(3.1)$ & 1 & & & \\
\hline No & $17284(44.0)$ & $363(2.1)$ & $0.8(0.6$ to 0.9$)$ & & & \\
\hline Not sure & $14081(35.8)$ & $308(2.2)$ & $0.7(0.6$ to 0.9$)$ & & & \\
\hline Participated in antitobacco activity & & & & $<0.001$ & & $<0.001$ \\
\hline Yes & $7675(19.5)$ & $288(3.8)$ & 1 & & 1 & \\
\hline No & $31607(80.5)$ & $626(2.0)$ & $0.6(0.5$ to 0.7$)$ & & $0.6(0.5$ to 0.7$)$ & \\
\hline Heard or seen antitobacco media messages & & & & $<0.001 \ddagger$ & & $<0.001 \ddagger$ \\
\hline None & $14106(35.9)$ & $291(2.1)$ & 1 & & 1 & \\
\hline $1-5$ & $10291(26.2)$ & $143(1.4)$ & $0.7(0.5$ to 0.9$)$ & & 0.7 (0.5 to 0.8$)$ & \\
\hline $6-10$ & $3597(9.2)$ & $184(5.1)$ & 1.8 (1.4 to 2.4$)$ & & 1.7 (1.4 to 2.2$)$ & \\
\hline$>10$ & $11288(28.7)$ & $296(2.6)$ & 1.2 (1.0 to 1.5$)$ & & $1.1(0.9$ to 1.4$)$ & \\
\hline Exposure to tobacco advertisements & & & & 0.442 & & \\
\hline Yes & $30111(76.7)$ & $743(2.5)$ & $1.1(0.9$ to 1.3$)$ & & & \\
\hline No & $9171(23.3)$ & $171(1.9)$ & 1 & & & \\
\hline Exposure to tobacco interval in movies & & & & $<0.001 \ddagger$ & & $<0.001 \ddagger$ \\
\hline 0 & $584(1.5)$ & $7(1.2)$ & 1 & & 1 & \\
\hline $1-48$ & $12079(30.7)$ & $363(3.0)$ & $1.2(0.6$ to 2.7$)$ & & $1.2(0.5$ to 2.6$)$ & \\
\hline $49-83$ & $13277(33.8)$ & $270(2.0)$ & $0.9(0.4$ to 1.9$)$ & & $0.9(0.4$ to 1.9$)$ & \\
\hline$>83$ & $13342(34.0)$ & $274(2.1)$ & $0.8(0.3$ to 1.7$)$ & & $0.7(0.3$ to 1.6$)$ & \\
\hline
\end{tabular}

*Model 1. All p<0.05 after adjustment for age, gender, father's education, family members smoking, friends smoking, wealth quintile, rebelliousness, self-esteem and school performance.

†Model 2. Mutually adjusted with exclusion of non-significant (NS) variables in this table.

$\ddagger \mathrm{P}$ value for trend.

Therefore, while our general findings indicate that children in this area of India take up smoking for similar reasons as those in richer countries, ${ }^{6}$ they also indicate that the effect of exposure to tobacco imagery in films in southern India may have less effect on smoking than in other countries. The most likely explanation for this is that the smoke-free film measures required in India since 2012 protect young people against harm from exposure to tobacco imagery.

India is a young nation, with half of the 1.3 billion population aged under 27 years. $^{25}$ In common with many other low and middle-income countries, the prevalence of smoking in India is low in relation to that in high-income countries, and especially so among women. ${ }^{26}$ Furthermore, smoking prevalence has, over recent years, been falling. Despite this trend, however, rapid population growth is generating increasing numbers of smokers, particularly among younger age groups, ${ }^{27} 28$ presaging a major future epidemic of tobacco-related death and disability. ${ }^{29}{ }^{30}$ If India is to avoid following the world's high-income countries down a path of major damage to public health from tobacco use $^{31}$ it is essential that the determinants of initiating tobacco

\begin{tabular}{|c|c|c|c|c|c|c|}
\hline Compliance to smoke-free film rules & $\mathrm{n}(\%)$ & Ever smoker (\%) & $\begin{array}{l}\text { Crude OR } \\
(95 \% \mathrm{CI})\end{array}$ & $P$ value & $\begin{array}{l}\text { Adjusted OR* } \\
(95 \% \mathrm{Cl})\end{array}$ & $P$ value \\
\hline AV disclaimer at the start of the film & & & & 0.039 & & 0.022 \\
\hline No & $7171(18.5)$ & $192(2.7)$ & 1.2 (1.0 to 1.4$)$ & & 1.3 (1.0 to 1.5$)$ & \\
\hline Yes & $31527(81.5)$ & $715(2.3)$ & 1 & & 1 & \\
\hline Health spot at the start of the film & & & & 0.861 & & 0.969 \\
\hline No & $2463(6.4)$ & $59(2.4)$ & 1.0 (0.8 to 1.3$)$ & & $1.0(0.7$ to 1.4$)$ & \\
\hline Yes & $36235(92.2)$ & $848(2.3)$ & 1 & & 1 & \\
\hline Health spot in the middle of the film & & & & 0.109 & & 0.391 \\
\hline No & $3234(8.4)$ & $89(2.8)$ & $1.2(1.0$ to 1.5$)$ & & $1.1(0.9$ to 1.5$)$ & \\
\hline Yes & $35464(91.6)$ & $818(2.3)$ & 1 & & 1 & \\
\hline Any static warning messages & & & & 0.329 & & 0.346 \\
\hline No & $223(0.6)$ & $3(1.3)$ & $0.6(0.2$ to 1.8$)$ & & $0.5(0.1$ to 2.1$)$ & \\
\hline Yes & 38475 (99.4) & $904(2.3)$ & 1 & & 1 & \\
\hline COTPA-compliant static warning messages & & & & 0.415 & & 0.261 \\
\hline No & 7944 (20.5) & $196(2.5)$ & $1.1(0.9$ to 1.3$)$ & & 1.1 (0.9 to 1.4$)$ & \\
\hline Yes & $30754(79.5)$ & $711(2.3)$ & 1 & & 1 & \\
\hline
\end{tabular}

${ }^{*}$ All $p<0.05$ after adjustment for age, gender, father's education, family members smoking, friends smoking, wealth quintile, rebelliousness, self-esteem and school performance. $\mathrm{AV}$, audiovisual; COTPA, Cigarettes and Other Tobacco Products Act. 
use in India are understood. The estimate in the present study of prevalence of ever smoking among young people in grades 6-8 of education, most of whom were aged 11-14 years, is based on a large population sample comprising $85 \%$ of eligible children in schools in the study district. It is therefore highly representative. The prevalence of ever smoking, at $2.3 \%$, in our survey conducted in 2017 was lower than the $4.4 \%$ national prevalence of current smoking reported in the 2009 GYTS in India, ${ }^{32}$ but the participants in our study were younger than GYTS participants, and from only one part of a country in which marked regional variations in prevalence have already been documented. ${ }^{24}$ Our figure is however broadly consistent with an earlier estimate of $4 \%$ ever use of smoked tobacco in the GYTS survey carried out in Karnataka in $2004^{33}$ and a study in similar age group students in Noida. ${ }^{34}$ Our figures do not include use of smokeless tobacco, which is in common use in India, ${ }^{35}$ and will be reported separately. The prevalence of current smoking in our sample was inevitably lower than that of ever smoking, and in view of the relatively small numbers involved we used ever smoking as our primary outcome to maximise study power.

Our finding that participants who had seen tobacco imagery in a range of locally popular films were not more likely to be ever smokers conflicts with a substantial literature demonstrating that exposure to smoking in films increases the risk of smoking, ${ }^{8}$ an association that is accepted by the US Surgeon General and other authorities to be causal. ${ }^{4-7}$ Our finding is therefore unexpected, suggesting that it is either a false negative or indicates that the effects of film exposure are getting diluted due to tobacco-free film and TV rules. The mediating role of these rules in explaining an association between tobacco use and tobacco imagery needs to be further investigated. If so, then the most likely explanation is attenuation by the COTPA tobacco-free film rules introduced in 2012, ${ }^{11}$ and our exploratory analysis suggests that of the several components of these measures, the presence of an AV disclaimer at the start of the film may be particularly important in this respect. However, the possibility that the effect of film tobacco imagery is offset by tobacco control messaging in films as a requirement of Indian tobacco control laws is consistent with the finding of an effect of film exposure on smoking among children in Delhi, conducted before the new tobacco control measures were introduced. ${ }^{10}$

One of the potential limitations of this study is that the models include variables which are correlated with each other, and while we have taken a strategic approach to deciding which variables to include in multivariate models, there remains a possibility of multicollinearity (ie, that effects may be dependent on the presence or absence of another correlated variable in the model). This study is, however, only a baseline description of findings

What this paper adds

- Exposure to smoking imagery in films has been shown to increase the risk of smoking uptake among adolescents and is causal.

- This article is the first to explore the impact of Indian smokefree laws on smoking uptake among adolescents in southern India.

- The study shows that children are no more likely to smoke if they have seen films containing smoking imagery.

- This paper also suggests that Indian smoke-free film rules might be successful in attenuating the impact of smoking imagery on children. in a cohort of children that has been followed prospectively over time, and we will report the prospective findings on the association between exposure to smoking imagery in films and subsequent smoking initiation in this cohort in further studies. We present these findings therefore as preliminary evidence that Indian tobacco control measures may have been successful in eradicating this important influence on smoking uptake.

\section{Twitter Veena Ganesh Kamath @MRC-UK Antitobacco}

Acknowledgements The authors thank the Deputy Director of Public Instructions of Udupi district for the permission, all the students who participated in the survey and the teachers for helping in the coordination. They also acknowledge the contributions of the research assistants and data collectors for their meticulous data collection.

Contributors JB and MMK conceptualised the study. The research plan was strengthened by $S L, J C, A K, A F, M A$ and VGK. Questionnaire was developed by MMK, JB, AF and IB and refined with inputs from MA, GPN, KB and VGK. Movie coding analysis was done by AK, JC, RB and GPN. Data collection in the field was coordinated by RB and supervised by MMK, KB, VGK and AK. The qualitative data analysis was done by AK and SL. Interpretation of data and drafting the manuscript were done by JB, MMK, IB, VGK, AK, SL and MA. Final approval of the version was read and approved by all authors.

Funding This work was supported by the Medical Research Council (grant number MR/P008933/1) of the UK under the Global Alliance for Chronic Lung Diseases programme.

Competing interests None declared.

Patient consent for publication Not required.

Ethics approval Ethics approval was granted by the Manipal and Nottingham University Ethics Committees, the Centre for Chronic Disease Control India, and the Health Ministry's Screening Committee.

Provenance and peer review Not commissioned; externally peer reviewed.

Data availability statement Data are available upon reasonable request. All the data are stored in anonymised form with the Co-PI of the research project. The metadata could be shared after obtaining regulatory approvals based on the purpose of requirement.

Open access This is an open access article distributed in accordance with the Creative Commons Attribution 4.0 Unported (CC BY 4.0) license, which permits others to copy, redistribute, remix, transform and build upon this work for any purpose, provided the original work is properly cited, a link to the licence is given, and indication of whether changes were made. See: https://creativecommons.org/ licenses/by/4.0/.

\section{ORCID iDs}

Muralidhar M Kulkarni http://orcid.org/0000-0003-3588-2165 Veena Ganesh Kamath http://orcid.org/0000-0002-0853-095X Gaurang P Nazar http://orcid.org/0000-0002-7025-2946

\section{REFERENCES}

1 World Health Organisation. Who global report on trends in prevalence of tobacco smoking 2015, 2015. Available: https://apps.who.int/iris/bitstream/handle/10665/ 156262/9789241564922_eng.pdf? sequence=1 [Accessed 5 Mar 2019].

2 World Health Organisation. Who report on the global tobacco epidemic, 2017. monitoring tobacco use and prevention policies. World Health Organisation, 2017. http://apps.who.int/iris/bitstream/10665/255874/1/9789241512824-eng.pdf?ua=1

3 WHO Framework Convention on Tobacco Control. Guidelines for implementation of Article 13 of the WHO Framework Convention on Tobacco Control (Tobacco advertising, promotion and sponsorship), 2008. Available: https://www.who.int/entity/ fctc/guidelines/article_13.pdf?ua=1 [Accessed 5 Mar 2019].

4 The National Cancer Institute. The Role of the Media in Promoting and reducing Tobacco Use. Tobacco Control Monograph No. 19. 2008. Available: http:// cancercontrol.cancer.gov/brp/tcrb/monographs/19/m19_complete.pdf

5 US Department of Health and Human Services. The Health Consequences of Smoking - 50 Years of Progress: A Report of the Surgeon General. Atlanta GA: 2014: U. S. Department of Health and Human Services, Centers for Disease Control and Prevention, National Center for Chronic Disease Prevention and Health Promotion, Office on Smoking and Health, 2014.

6 U.S.Department of Health and Human Services. Preventing tobacco use among youth and young adults: a report of the surgeon General. Atlanta GA: U.S. Department of Health and Human Services, Centers for Disease Control and Prevention, National Center for Chronic Disease Prevention and Health Promotion, Office on Smoking 
and Health, 2017. https://www.surgeongeneral.gov/library/reports/preventing-youthtobacco-use/index.html2012

7 World Health Organisation. Smoke-Free movies: from evidence to action. 3rd edition, 2015. Available: http://apps.who.int/iris/bitstream/10665/190165/1/ 9789241509596_eng.pdf?ua=

8 Leonardi-Bee J, Nderi M, Britton J. Smoking in movies and smoking initiation in adolescents: systematic review and meta-analysis. Addiction 2016;111:1750-63.

9 World Health Organisation. 'Bollywood': victim or ally? A who study on the portrayal of tobacco in Indian cinema, 2003. Available: http://www.who.int/tobacco/media/en/ bollywood-exesum.pdf

10 Arora M, Mathur N, Gupta VK, et al. Tobacco use in Bollywood movies, tobacco promotional activities and their association with tobacco use among Indian adolescents. Tob Control 2012;21:482-7.

11 Kulkarni MM, Kamath VG, Cranwell J, et al. Assessment of tobacco imagery and compliance with tobacco-free rules in popular Indian films. Tob Control 2020;29:119-21.

12 Reddy KS, Gupta PC. Tobacco control in India. New Delhi: Ministry of Health and Family Welfare, Government of India, 2004: 43-7.

13 Centers for Disease Control and Prevention. Global Youth Tobacco Survey (GYTS) Core Questionnaire with Optional Questions. CDC/WHO, 2012. Available: https://nccd.cdc. gov/GTSSData/Ancillary/DownloadAttachment.aspx?ID=33 [Accessed 13 Dec 2016].

14 NHS Digital. Smoking drinking and drug use among young people in England in 2016, 2017. Available: http://digital.nhs.uk/media/33663/Smoking-Drinking-and-Drug-UseAmong-Young-People-in-England-2016-Report/default/sdd-2016-rep [Accessed 28 Nov 2017].

15 Reddy KS, Perry CL, Stigler MH, et al. Differences in tobacco use among young people in urban India by sex, socioeconomic status, age, and school grade: assessment of baseline survey data. Lancet 2006:367:589-94.

16 Spanopoulos D, Britton J, McNeill A, et al. Tobacco display and brand communication at the point of sale: implications for adolescent smoking behaviour. Tob Control 2014;23:64-9.

17 Bogdanovica I, Szatkowski L, McNeill A, et al. Exposure to point-of-sale displays and changes in susceptibility to smoking: findings from a cohort study of school students. Addiction 2015;110:693-702.

18 Ministry of Law and Justice. The Cigarette and Other Tobacco Products (Prohibition of advertisement and regulation of trade and commerce, production, supply and distribution) Act 2003 [Internet], 2003. Available: http://www.who.int/fctc/reporting/ Annexthreeindia.pdf [Accessed 06 Mar 2019].

19 Ministry of Health and Family Welfare. Notification G.S.R.708(E). Gazette of India, 2012. Available: https://www.tobaccocontrollaws.org/files/live/India/India\%20-\%20G. S.R.\%20708\%28E\%29.pdf [Accessed 17 Mar 2019].

20 Molyneux A, Lewis S, Antoniak M, et al. Is smoking a communicable disease? effect of exposure to ever smokers in school tutor groups on the risk of incident smoking in the first year of secondary school. Tob Control 2002;11:241-5.
21 Molyneux A, Lewis S, Antoniak M, et al. Prospective study of the effect of exposure to other smokers in high school tutor groups on the risk of incident smoking in adolescence. Americal Journal of Epidemiology 2003.

22 Elton-Marshall T, Fong G, Fotuhi O, et al. Rebelliousness, depression and smoking among youth in Thailand and Malaysia: findings from the ITC Southeast Asia project, 2007. Available: https://www.itcproject.org/files/Elton-Marshall_et_al._2007. Rebelliousness,_depression_and_smoking_among_youth_in_TH_and_MY._NCTH. pdf

23 Smith GD, Gordon D, Kelly M, et al. Inequalities in health in India: the methodological construction of indices and measures, 2003. Available: https://www.bristol.ac.uk/ poverty/downloads/healthinequalities/Methodology\%20report.doc [Accessed 19 Feb 2019].

24 Singh A, Ladusingh L. Prevalence and determinants of tobacco use in India: evidence from recent global adult tobacco survey data. PLoS One 2014;9:e114073

25 United Nations. World population prospects: The 2017 revision. United Nations Department of Economic and Social Affairs. Available: https://population.un.org/wpp/ DataQuery/ [Accessed 20 Feb 2019].

$26 \mathrm{Ng} \mathrm{M}$, Freeman MK, Fleming TD, et al. Smoking prevalence and cigarette consumption in 187 countries, 1980-2012. JAMA 2014;311:183-92.

$27 \mathrm{Ng} \mathrm{M}$, Freeman MK, Fleming TD, et al. Modeled prevalence of daily smoking and estimated cigarette consumption in 187 countries, 1980-2012: India, 2014. Available: http://jama.jamanetwork.com/multimediaPlayer.aspx?interactivelD $=6358516$

28 Mishra S, Joseph RA, Gupta PC, et al. Trends in bidi and cigarette smoking in India from 1998 to 2015, by age, gender and education. BMJ Glob Health 2016;1:e000005.

29 Lopez AD, Collishaw NE, Piha T. A descriptive model of the cigarette epidemic in developed countries. Tob Control 1994;3:242-7.

30 Thun M, Peto R, Boreham J, et al. Stages of the cigarette epidemic on entering its second century. Tob Control 2012;21:96-101.

31 Lim SS, Vos T, Flaxman AD, et al. A comparative risk assessment of burden of disease and injury attributable to 67 risk factors and risk factor clusters in 21 regions, 1990 2010: a systematic analysis for the global burden of disease study 2010. Lancet 2012;380:2224-60.

32 World Health Organisation. India (ages 13-15) global youth tobacco survey fact sheet 2009. Available: http://www.searo.who.int/entity/noncommunicable diseases/data/ ind_gyts_fs_2009.pdf?ua=1 [Accessed 20 Feb 2019].

33 Gururaj G, Girish N. Tobacco use amongst children in Karnataka. Indian J Pediatr 2007;74:1095-8

34 Narain R, Sardana S, Gupta S, et al. Age at initiation \& prevalence of tobacco use among school children in Noida, India: a cross-sectional questionnaire based survey. Indian J Med Res 2011;133:300-7.

35 Bhawna G. Burden of smoked and smokeless tobacco consumption in India - results from the Global adult Tobacco Survey India (GATS-India)- 2009-201. Asian Pac J Cancer Prev 2013;14:3323-9. 